Safely" (2011) were developed encompassing the various characteristics of children throughout their development and providing corresponding harm reduction principles.

These posters identify the early developmental limitations of the children; recognise typical injuries within specified age groups (from the database); illustrate the best practice scenario and best prevention are organised by age and are coloured with detailed pictures of accident precautions and suggestions.

Results "Growing Safely" is an international award winning poster and depicts the child from birth until age six. It raises crucial awareness by providing safety recommendations, by age, for fall prevention, drowning risks, car safety, and the dangers of common household items.

The "Living Safely" poster was designed in response to a growing number of hot water burns and flame burns. Thus, "Living Safely" is formatted in the same award winning design and addresses burn risks and fire safety. The topics portrayed in "Living Safely" include; sunburn protection, hot water burn prevention, electrical cord/outlet recommendations, and proper fire extinguishing directions.

The most recently developed poster, "Travelling Safely" illustrates age appropriate vehicle restraints, helmet and safety guard suggestions, street crossing advisory, and tips for proper bicycling. To provide such imperative information, the three posters have been translated into local languages.

Conclusion The Childsafe South Africa posters have been well received and regarded as best educational tool not only in South Africa but around the world. People are able to connect with messages as it's extracted from simple situations that take place on daily basis. Images of real people (children) are being used and the pictorial depictions overcome literacy levels.

\section{WALK SAFE CAMPAIGN: A RAIL-ROAD COMMUTERS' SAFETY PROGRAM WITH RAILWAYS (SINCE 2012 AND CONTINUED)}

${ }^{1}$ Rajni Gandhi. Trax Sports Society, Member of Global Alliance of NGOs for Road Safety, International Road Federation (INDIA Chapter)

\subsection{6/injuryprev-2016-042156.942}

Background The 'High Level Safety Review Committee' (appointed by Railway Ministry, Government of India) report2012 states that the estimation is almost 15000 persons get killed in on the entire railway system every year. During 2007-08 to October, 2011, 1600 Railway Staff was killed and another 8700 people were injured due to railway accidents. It is to be noted that casualties in train accidents include a large chunk of deaths and injuries due to unmanned level crossing accidents attributed to the negligence of road users.

Methods With the objective to sensitise daily Railway commuters about developing good Safety Habits as Railway Commuters and Road Users, we devised a Specialised/Trained team. This team conducts Workshops, Performs Street Plays and Distributes Educational Pamphlets and interacts with target group members. Under this campaign we have covered different sections falling under different divisions of Northern and North-Central Railways.

Target Locations - Schools, Colleges, Traffic Intersections, Railway Platforms, Unmanned Railway Crossings

Area Covered - Urban and Rural

States Covered - Haryana, Uttar Pradesh, Punjab, Rajasthan and Delhi

Results This is an ongoing operation the impact of such campaigns need to be evaluated over a readably period. However, on the spot response has been encouraging and positive.

Conclusions The existing campaign has been planned for Northern and Northern Central Division. We plan to take it further to other divisions of Railways in coming years. It is expected that the $50 \%$ of the entire Railways network would be covered in the next five years.

\section{RISK FACTORS PREDISPOSING TO ROAD TRAFFIC INJURY IN YOUNGSTERS: A CASE-CONTROL STUDY}

${ }^{1,2}$ Mohamed Mouloud Haddak. 'University of Lyon, France; ${ }^{2}$ Ifsttar-Umrestte, France

\subsection{6/injuryprev-2016-042156.943}

Background Youngster injury is the leading cause of mortality, morbidity and permanent disability in adolescent in the developed world. The objective of this research is to study the joint effect of family and contextual socioeconomic characteristics of teenagers on their risk of road accidents, taking into account their mobility practices, their behaviour and their attitude to risk.

Methods A case-control study was conducted on a population of 601 young people aged 14-17, in 2013. Cases (208 subjects) were selected from the Rhône Road Trauma Registry. Controls (393 subjects) adjusted by age and sex were randomly selected by telephone. L'exposition à la circulation routière est mesurée pour chaque mode de transport utilisé par le budget-temps. The relationships between SES status, urban/periurban-rural location, mode of transport, mobility practice, and injury type were determined using conditional logistic regression. Exposure to road traffic is measured for each mode of transportation used by the weekly time budget.

Results The intensive use of motorised two-wheelers holds an essential role in the risk of road accidents between 14 and 17 years $(\mathrm{OR}=4.1[2.3-7.2])$, followed by regular cycling $(\mathrm{OR}=3.6[2.0-6.5])$ and skating $(\mathrm{OR}=1.9$ [1.1-3.1]). Socioeconomic status of young people is highlighted: students in professional college or young apprentices are at higher risk $(\mathrm{OR}=2.1[1-4.3])$. Compared with urban adolescents, adolescents living in rural areas suffer a 1.9 higher risk (1.9 [1.2-3.0]). The links between road risk behaviour and smoking are also underlined (OR $=4.4$ [2-9.7]).

Conclusions These results show that adolescent road traffic injury in Rhône is a major health concern, especially among motorcyclist males (40\% of the injuries) from rural area and from lower SES. But this study also shows the significant impact of behavioural factors (tobacco, cannabis) on the risk of accident. 


\section{Epidemiology}

\section{Post Wed 3.3}

\section{FALLS RELATED INJURIES IN BANGLADESH: EXPERIENCES FROM A COMMUNITY-BASED SURVEILLANCE SYSTEM}

Salim Mahmud Chowdhury, Abu Taleb, Fazlur Rahman. Centre for Injury Prevention and Research, Bangladesh (CIPRB)

\subsection{6/injuryprev-2016-042156.944}

Background Injuries have become a major public health concern in Bangladesh due to epidemiological transition. Falls among children is one of the leading cause of childhood morbidity in Bangladesh. Falls among adults has great impacts on our economy as falls is a major cause of permanent and long-term disability. However, falls among whole population has not yet been studied. In this study, we aimed at exploring the distribution and determinants of falls among all age groups.

Methods A community-based active surveillance system covering around 150,000 population was developed in three unions (lowest administrative infrastructure) of a sub-district of Sirajgonj district, Bangladesh in 2005. Every year, four rounds of data are being collected from the each and every households of the surveillance areas by the trained surveillance data collectors. One year data (July 2009 to June 2010) generated from this surveillance system was analysed for this study.

Findings Rate of non-fatal falls was higher among children $(<18$ years) than adults (405.24 and 304.60 per 100,000 population per year respectively). Falls from the same level (67.1\%) was significantly higher that falls from height $(32.9 \%)$ and slipping or tripping was the main mechanism for falls from the same level. Most of the falls occurred in the sport areas (18.9\%) followed by street (17.2\%). Accidental falls was the main mechanism for falls from height $(32.6 \%)$. For falls from height, trees were identified as the most common place $(40.7 \%)$ whereas height of the most of the incidents were less than 1 metre. Most of the falls occurred in the yards (34.6\%). Mean days for school loss among the injured students were $13.39 \pm 14.15$ while workday loss among injured person was $12.65 \pm 14.54$. Among the productive age groups, most of the injured persons were the main income earners of the family.

Conclusion Considering the extent of falls in Bangladesh, the issue needs to be addressed on priority basis. Findings of this study could be a knowledgebase for developing an evidencebased intervention to address the issue.

\section{ACCURACY OF SHORT-TERM FORECASTING OF OCCURRENCE OF MOTORCYCLE INJURY USING TIME SERIES ANALYSIS}

Aratta Rangpueng, Panithee Thammawijaya. Bureau of Epidemiology, Department of Diseases Control,Ministry of Public Health, Thailand

\subsection{6/injuryprev-2016-042156.945}

Background Disease forecasting is useful for effective planning of prevention and control program. Time series analysis is one of quantitative methods applied in disease forecasting. Motorcycle injury was a major problem in Thailand. It was reported each year 54000-61000 cases and cases, including 3000-4000 deaths. Most of severe injury case under 15 years old was 5,000-6,000 and 200 died annually. Objective of the study is to compare accuracy between the Exponential Smoothing (ES) and Autoregressive Integrated Moving Average (ARIMA) Models for short-term forecasting of motorcycle injury, in order to estimates of the magnitude of problems, and prepare resources for injury prevention and control.

Methods Monthly data of motorcycle injury numbers from 2006-2014 were collected from Thailand National Injury Surveillance System. Two forecasting methods with the criterion of minimum Mean absolute error (MAE) and Mean Absolute Percent Error (MAPE) based on 2006-2010 data. The selected ES and ARIMA models then were applied for forecasting number of injury in 2011-2014. MAE and MAPE of one-, two-, three-, and four-month forecasting were compared between the two models. $\mathrm{P}$ value from paired t-test was calculated for each comparison.

Results The result showed that, in terms of forecasting accuracy, Exponential Smoothing (Simple Seasonal) model performed better than ARIMA $(1,0,0)(1,1,1)$ model. MAPE of the forecasts from ES at one-, two-, three-, and four-month were $2.7 \%$, $6.1 \%, 7.5 \%$ and $7.9 \%$ respectively, while those from ARIMA methods were $3.0 \%, 6.4 \%, 7.8 \%$ and $8.3 \%$ respectively.

Conclusions We suggested that the Exponential Smoothing (Simple seasonal) should be used as a tool to provide affordable and reliable short-term forecast of motorcycle accident.

\section{PERIL IN PARADISE: AN EPIDEMIOLOGICAL ANALYSIS OF INJURIES IN TROPICAL NORTH QUEENSLAND, AUSTRALIA}

${ }^{1}$ Kerrianne Watt, ${ }^{1}$ Jane Mills, ${ }^{1}$ Nicky Neighbour, ${ }^{1}$ Linton Harris, ${ }^{1}$ Richard Franklin, ${ }^{2}$ Neil Beaton, ${ }^{2}$ Don Wyatt. ${ }^{1}$ James Cook University; ${ }^{2}$ Cairns Hospital Emergency Department

\subsection{6/injuryprev-2016-042156.946}

Background Tropical North Queensland is a popular national and international tourist destination in Queensland, Australia. Approximately 2000000 tourists visit the region annually; there are approximately 150000 residents. Tourists and residents participate in activities like bushwalking in the surrounding rainforests, swimming/snorkelling/diving in the Great Barrier Reef, and a range of adventure sports. Consequently, exposure to a range of venomous creatures and other risky situations is higher than usual. Cairns Hospital is the main public hospital in the region; the annual throughput of the Emergency Department (ED) is 60000 presentations. The purpose of this study was to investigate the epidemiological characteristics of the injuries treated at Cairns Hospital ED over a 4 yr period.

Methods Data were obtained regarding all injury presentations at the Cairns Hospital Emergency Department over 4 yrs $\left(1^{\text {st }} \mathrm{Jan}\right.$ 2010-31 ${ }^{\text {st }}$ Dec 2013). Descriptive analyses were completed to determine the epidemiological characteristics of these injury presentations (via SPSS).

Results There were 55,475 injury episodes treated at the Cairns Hospital ED over the study period, comprising 25.73\% of all presentations to the ED. Injury was the leading cause for ED presentation over the $4 \mathrm{yr}$ period. The proportion of injury presentations did not vary significantly over time. $15 \%$ of injury episodes involved tourists $(3.6 \%$ interstate, $3.7 \%$ international, $7.5 \%$ from elsewhere in Queensland). Interstate tourists and tourists from elsewhere in Queensland were significantly more likely to be hospitalised as a consequence of their injury than residents of North Queensland (29\% vs 22\%; p < 0.001), and international tourists were less likely to require hospitalisation (17\%). Every year from 